\title{
Reutilização de Registos Clínicos para Investigação Científica: Questões Jurídicas Relacionadas com a Autorização dos Titulares e a Anonimização
}

\section{Reuse of Clinical Records for Scientific Research: Legal Issues Related to the Authorization of the Holders and Anonymisation}

\author{
Rui GUIMARÃES ${ }^{1,2,3, *}$, Pedro RODRIGUES ${ }^{2, *}$, Agostinho SANTOS $^{1, *}$, Ricardo Jorge DINIS-OLIVEIRA $\triangle^{1,4,5, *}$ \\ Acta Med Port 2018 Jun;31(6):299-302 - https://doi.org/10.20344/amp.10147
}

Palavras-chave: Anonimização de Dados; Confidencialidade; Investigação Biomédica; Portugal; Privacidade; Registos Electrónicos de Saúde

Keywords: Biomedical Research; Confidentiality; Data Anonymization; Electronic Health Records; Portugal; Privacy

\section{INTRODUÇÃO}

A comunidade científica, particularmente a clínica, cada vez atribui mais importância à reutilização dos registos clínicos com origem na prestação de cuidados. ${ }^{1-3}$ Os argumentos a favor e contra sucedem-se, com instituições hospitalares, universidades e centros de investigação a fazerem enormes investimentos para que informação não estruturada, cujo objetivo foi representar atos de prestação de cuidados, possa ser utilizada na investigação científica de índole clínica. ${ }^{2}$

É neste quadro e com estas motivações que os autores, no decurso das suas atividades científicas e académicas universitárias, e no desempenho de funções legais de Responsável pelo Acesso à Informação (RAI) do Centro Hospitalar de São João (CHSJ), se propõem refletir sobre a anonimização (ou a sua inexistência) dos registos clínicos. A abordagem desta temática será feita com o esclarecimento rigoroso, preciso e inequívoco de duas questões prévias e fundamentais: i) a investigação com base nos registos clínicos eletrónicos ou em papel, oriundos da prestação de cuidados; e ii) as considerações em matéria do Direito, a que se seguem interpretações, propostas de resolução, e perspetivas futuras.

Bens jurídicos que o legislador pretende proteger quando invoca a autorização dos titulares dos registos clínicos, ou a anonimização dos mesmos

Saber quais os bens jurídicos que pretende o legislador tutelar quando invoca a autorização dos titulares dos registos clínicos, ou a anonimização dos mesmos, como requisitos para viabilizar juridicamente a reutilização é uma questão de extrema importância. Por isso, é crucial perceber qual é a mens legis, o espirito e que preocupações tem o legislador quando fala naqueles dois requisitos. O mais elementar exercício epistemológico dá-nos a resposta: assegurar a privacidade, a confidencialidade, o direito à intimidade da vida privada do titular dos registos clínicos e o sigilo institucional e o das pessoas singulares. Ora tal não se faz, nem com a autorização do titular dos registos, sem mais, e muito menos com um requisito praticamente impossível de cumprir, como a anonimização sem possibilidade de reversão.

De facto, o conhecimento empírico da realidade conflitua frontalmente com estas vias escolhidas pelo legislador. $\mathrm{Na}$ verdade, os registos clínicos solicitados pelo investigador são documentos nominativos, e nessa medida a sua reutilização está sujeita a autorização do titular dos mesmos, ou a uma anonimização sem possibilidade de reversão por parte das unidades do sistema de saúde com a obrigação legal da guarda de tal património informacional, ou a disposição legal que a preveja expressamente. A este respeito importa ter presente que a autorização do titular dos registos clínicos para os mesmos poderem ser reutilizados para fins de investigação clínica, os investigadores não as exibem, nem as afirmam ter, pela simples razão de que não as têm. Não faz parte (e nunca fez) das práticas médicas, nem da cultura das organizações hospitalares e, como referido por Walter Osswald, "do ponto de vista prático, seria inviável solicitar autorização do titular, entretanto falecido, emigrado, sem morada conhecida ou incapaz".

Sobre o consentimento, a sua pertinência, e o eventual viés que pode causar na investigação, importa trazer à colação e recordar Maria João Bernardes que põe em causa

\footnotetext{
${ }^{*}$ Co-primeiros autores.

1. Department of Public Health, Forensic Sciences and Medical Education. Faculty of Medicine. University of Porto. Porto. Portugal.

2. MEDCIDS - Community Medicine, Health Information and Decision Department. Faculty of Medicine. University of Porto. Porto. Portugal.

3. Hospital Centre São João. Porto. Portugal.

4. Department of Sciences. Institute of Research and Advanced Training in Health Sciences and Technologies. Institute of Health Sciences. Gandra. Portugal.

5. UCIBIO-REQUIMTE - Laboratory of Toxicology. Department of Biological Sciences. Faculty of Pharmacy. University of Porto. Porto. Portugal.

$\triangle$ Autor correspondente: Ricardo Jorge Dinis-Oliveira. ricardinis@sapo.pt

Recebido: 27 de dezembro de 2017 - Aceite: 07 de maio de 2018 | Copyright $\odot$ Ordem dos Médicos 2018
} 
a necessidade de consentimento obrigatório, defendendo que "embora a sua obtenção seja teoricamente desejável, podendo proteger autores e editores de problemas médico-legais, o mesmo poderá não ser possível e não ser verdadeiramente livre, informado e indicado, não contribuindo para uma proteção efetiva dos doentes, mas funcionando antes como um elemento de garantia exclusiva do cumprimento de quesitos de índole legal pura" ${ }^{5} \mathrm{E}$ acrescenta ainda, com uma clarividência impar que "falta provar inequivocamente que o consentimento escrito obrigatório proteja melhor o direito do doente à autonomia e à confidencialidade do que o simples consentimento não escrito ou, mesmo, a ausência de consentimento; referem ainda que muitos dos casos em que é dado o consentimento poderão corresponder a situações de maior ou menor gravidade da doença ou vulnerabilidade do doente". ${ }^{5}$ De notar ainda que o acesso do investigador aos registos clínicos de um doente é sempre escrutinável pelo próprio titular dos registos através do portal do utente, área do cidadão, dados pessoais, autorizações, opção "quero ser notificado, quando um profissional de saúde, credenciado, consultar a minha informação clínica registada".

Quanto à anonimização, importa ter presente que no Direito português, quer a lei do acesso e reutilização, quer a lei de proteção de dados pessoais, ambas transposições para o ordenamento jurídico nacional de Diretivas do Parlamento Europeu e do Conselho, falam em anonimização sem fazerem, à semelhança de outros conceitos, a sua definição. No Direito europeu, o legislador, fala em pseudoanonimização e define-a de forma clara e inequívoca. Há pois uma divergência clara na utilização de conceitos no Direito português e no Direito europeu. Pseudoanonimização é, de acordo com o Regulamento 2016/679 do Parlamento Europeu e do Conselho de 27/04/2016, “(...) o tratamento de dados pessoais para que deixem de poder ser atribuídos a um titular de dados específico sem recurso a informações suplementares, desde que essas informações suplementares sejam mantidas separadamente e sujeitas a medidas técnicas e organizativas para assegurar que os dados pessoais não possam ser atribuídos a uma pessoa singular identificada ou identificável". Por outro lado, anonimizar sem possibilidade de reversão é uma expressão e conceito que infelizmente o legislador nacional não definiu. Mesmo que desidentificados ou até eventualmente anonimizados, os dados não deixam de conter informação potencialmente confidencial, pelo que continua a ser fundamental precaver obrigações de sigilo profissional. Por tudo isto, trabalhar com anonimização de dados pessoais significa saber gerir o risco.

Independentemente de todas estas questões, o que a nossa lei consagra, é a anonimização dos registos clínicos, na forma irreversível, responsabilizando as unidades de saúde por essa tarefa. Tal é um mito jurídico, uma utopia reveladora de um completo desconhecimento quer da realidade quer das potencialidades das tecnologias de informação e comunicação hoje disponíveis. ${ }^{6,7}$ Trata-se sim de um exemplo em que a realidade ultrapassou as diretivas legais e lhes retirou o sentido regulador. Ora o Direito jamais pode ser um mito ou uma utopia, admiti-lo seria negar-se nas suas razões e fundamentos. A anonimização dos registos clínicos assim prevista, obviamente bem-intencionada, é, no mínimo, um lapso do legislador, um elemento de entropia que em nada contribui para a concretização dos direitos e interesses, quer dos titulares dos registos clínicos, quer dos investigadores, quer ainda das instituições, sejam elas hospitalares, universitárias ou centros de investigação, com consequências perniciosas para a investigação científica, pela perda de qualidade da informação. $8,9,10$

\section{Propostas de resolução}

A questão que se nos coloca é a de como cumprir a lei. Como pode então um investigador reutilizar registos clínicos com origem na prestação de cuidados de saúde, quando não tem autorização do titular dos mesmos para o fazer? Por outro lado, sabemos hoje ser praticamente impossível anonimizar de forma irreversível um registo clínico. Acresce que não podemos deixar de cumprir a lei e a mens legis, cuja preocupação, como já foi aqui referido, é preservar e garantir a privacidade, a confidencialidade, o direito à intimidade da vida privada do titular dos registos clínicos, o sigilo institucional e o das pessoas singulares, a que uns e outros estão vinculados juridicamente.

As decisões, suportadas na nossa tese jurídica, fundamentam-se numa antropologia filosófica, com o homem como ser preponderante, a investigação científica como bem de interesse público e constrói-se num equilíbrio assente nos seguintes pressupostos:

a) De acordo com a Lei n. ${ }^{\circ}$ 26/2016, 22 de agosto (transposição da Diretiva 2003/4/CE, do Parlamento Europeu e do Conselho, de 28 de janeiro, e a Diretiva 2003/98/ CE, do Parlamento Europeu e do Conselho, de 17 de novembro) que aprova o regime de acesso à informação administrativa e ambiental e de reutilização dos documentos administrativos há, inequivocamente, por parte do investigador, o direito de ter acesso para fins de reutilização, a registos clínicos, que são documentos nominativos, sempre que "demonstrar, fundamentadamente, ser titular de um interesse direto, pessoal, ou funcional, legítimo e constitucionalmente protegido, suficientemente relevante, após ponderação do pedido em apreço, no quadro do princípio da proporcionalidade, de todos os direitos fundamentais em presença, do princípio da administração aberta, da sociedade do conhecimento, fundamento da reutilização, que justifique o acesso à informação";

b) A investigação científica de índole clínica tem, obrigatoriamente, inerente o interesse público de contribuir para o aumento do conhecimento científico e clínico em prol do ser humano e para servir as pessoas, pois a ciência não existe até estar publicada';

c) O acesso a dados que, no campo da investigação científica de índole clínica, é consentido para reutilização não tem qualquer impacto em desfavor do proprietário dos registos, nem na esfera clínica dos titulares dos 
mesmos, senão mediato, e favorável, por se ter atingido maior conhecimento científico, o que configura, por via da regra, um potencial benefício para o titular dos registos clínicos;

d) Igualmente não tem impacto na esfera jurídica dos titulares dos registos clínicos, já que a privacidade, a confidencialidade e o direito à intimidade da vida privada dos titulares desses registos clínicos, o sigilo institucional e o das pessoas singulares, a que uns e outros estão vinculados juridicamente, valores que o espírito da lei pretende garantir com a autorização do titular ou anonimização dos registos clínicos, ficam assegurados na 'Aceitação dos Termos e Condições da Reutilização' assinada pelo investigador aquando da formalização do pedido, constituindo assim uma vinculação jurídica, cuja violação é passível do apuramento de responsabilidades disciplinares, civis e penais ${ }^{1}$;

e) Se a investigação tivesse por objeto a experimentação de um fármaco, de uma técnica cirúrgica, de uma nova abordagem médica, de um novo dispositivo, o consentimento informado, face aos riscos potenciais, revelar-se-ia indispensável, o que aqui não é, manifestamente, o caso;

f) $\mathrm{Na}$ investigação que reutiliza registos clínicos com origem na prestação de cuidados, ao invés, há lugar a uma análise científica sobre práticas e factos pretéritos, cuja fonte de informação são registos clínicos que resultaram da prestação de cuidados feita aos seus titulares, pelo que a sujeição à autorização podia mesmo constituir um viés na investigação; mais, não se percebe, como e em que medida, a autorização do titular podia funcionar, de per si, como garantia da sua privacidade, confidencialidade, do seu direito à intimidade da vida privada, ou do sigilo institucional e das pessoas singulares, a que uns e outros estão vinculados juridicamente, sem uma contrapartida de vinculação jurídica por parte do investigador, matéria em que a lei é omissa;

g) A inexistência da autorização do titular dos registos clínicos para acesso e reutilização com o fim de investigação cientifica de índole clínica, realidade com expressão em todo o Serviço Nacional de Saúde, pode e deve ser colmatada, pela estatuição jurídica da verificação da existência, ou não, pelo RAI, relativamente ao investigador, do direito deste ter acesso para fins de reutilização, a registos clínicos, que são documentos nominativos, se demonstrar, fundamentadamente, ser titular de um interesse direto, pessoal, ou funcional, legítimo e constitucionalmente protegido, suficientemente relevante, após ponderação do pedido em apreço, no quadro do princípio da proporcionalidade, de todos os direitos fundamentais em presença, do princípio da administração aberta, que justifique o acesso à informação, num equilíbrio de todos os direitos e obrigações em presença, quer sejam do titular dos registos clínicos, quer do investigador, quer ainda, dos interesses das instituições universitárias, hospitalares e de investigação, concomitantemente com a vinculação jurídica instituída na 'Aceitação dos Termos e Condições da Reutilização'.

Neste momento, a via para garantir os direitos do titular dos registos, tem que ser necessariamente através da responsabilização por vinculação jurídica do investigador, que por inerência ao direito de o ser, e como consequência de o ser, isto é, por ter o direito de investigar, tem o direito de reutilizar registos clínicos com origem na prestação de cuidados. Ora, no plano estritamente jurídico, que é especificamente o da nossa abordagem e tem natureza imperativa, a esses direitos correspondem obrigações, também elas jurídicas e indeclináveis, as quais estão instituídas na 'Aceitação dos Termos e Condições da Reutilização', assinadas pelo investigador aquando da formalização do pedido disponível no sítio web do Centro Hospitalar de São João, EPE em 'Pedido de Reutilização de Registos Clínicos para Investigação e Desenvolvimento (I\&D)'. É por isso nossa convicção do relevante papel das instituições (e.g., hospitais, faculdades, ou centros de investigação) enquanto fiéis depositários das fontes de informação a utilizar na investigação, ou na sua qualidade de entidades que tutelam a investigação, não podem deixar de ser num duplo patamar: i) criar o Estatuto do Investigador como um instrumento de vinculação jurídica e de responsabilidade ética, é o que esta nossa tese faz com a 'Aceitação dos Termos e Condições da Reutilização'; e ii) introduzir a certificação da transparência e da reprodutibilidade da investigação, como instrumento de combate à fraude na investigação, que é o que fazemos com o DAtaREuseCertificate for Research (DARE).

\section{Conclusões e perspetivas futuras}

Por tudo isto, a tese que aqui defendemos e que suporta as responsabilidades diárias que assumimos, viabiliza fundamentadamente os direitos dos investigadores, os interesses e obrigações das instituições, e, acima de tudo, dá aos titulares dos registos clínicos reutilizados na investigação científica de índole clínica as necessárias garantias de proteção pela lei do acesso e reutilização e pode ser auditada. À semelhança, nos mesmos termos e com os mesmos fundamentos com que foi criado o Registo Nacional de Não Dadores para as pessoas que não desejam doar órgãos após a sua morte, no futuro, sem prejuízo da vinculação jurídica que defendemos, não nos repugnaria a aplicação de um princípio de solidariedade presumida para fins de autorização para a utilização de registos clínicos oriundos da prestação de cuidados, para fins de investigação. O silêncio dos doentes titulares dos registos clínicos pode ser interpretado como uma manifestação de concórdia e de maturidade cívica e de solidariedade com a investigação científica e com o almejar da sociedade do conhecimento e, bem assim, com a convicção inequívoca de ele próprio, ser, sempre, beneficiário da investigação. Ademais, neste contexto, mais do que desadequados, os consentimentos informados podem constituir um viés à investigação e nessa medida um fator de entropia. 


\section{AGRADECIMENTOS}

Os Autores agradecem a Walter Osswald a leitura crítica deste texto e as sugestões apresentadas. A Maria João Bernardes, na pessoa do seu pai, João Bernardes, fica igualmente um agradecimento pelo rigor intelectual $\mathrm{e}$

\section{REFERÊNCIAS}

1. Guimarães R, Dinis-Oliveira RJ, Pereira A, Rodrigues P, Santos A. Reutilização de informação clínica para investigação: o modelo da pegada científica do Centro Hospitalar de São João. Acta Med Port. 2017;30:159-62.

2. Song M, Liu K, Abromitis R, Schleyer TL. Reusing electronic patient data for dental clinical research: a review of current status. J Dent. 2013;41:1148-63.

3. Dinis-Oliveira RJ, Magalhães T. Teaching and learning based on peer review: a realistic approach in forensic sciences. F1000Res. 2016;5:1048.

4. Smith R. Opening up BMJ peer review: a beginning that should lead to complete transparency. BMJ. 1999;318:4-5.

5. Bernardes MJ, Nunes R. Consentimento dos doentes para a publicação de casos clínicos: revisão da literatura. Arq Med. 2013;27:58-64.

6. Committee on Strategies for Responsible Sharing of Clinical Trial Data, Board on Health Sciences Policy, Institute of Medicine of the National fonte de inspiração que representou na abordagem de tão complexo tema.

Ricardo Dinis-Oliveira agradece à Fundação para a Ciência e a Tecnologia (FCT) pela sua Investigator Grant (IF/01147/2013).

Academies. Appendix B - Concepts and methods for de-identifying clinical trial data. In: Sharing clinical trial data: maximizing benefits, minimizing risk. Committee on Strategies for Responsible Sharing of Clinical Trial Data, Board on Health Sciences Policy \& Institute of Medicine of the National Academies edtiros. Washington: The National Academies Press; 2015. p. 203-90.

7. Ohm P. Broken promises of privacy: responding to the surprising failure of anonymization. UCLA Law Review. 2010;57:1701-77.

8. Dinis-Oliveira RJ, Magalhães T. The inherent drawbacks of the pressure to publish in health sciences: good or bad science. F1000Res. 2015;4:419.

9. Heatherly R, Rasmussen LV, Peissig PL, Pacheco JA, Harris P, Denny $\mathrm{JC}$, et al. A multi-institution evaluation of clinical profile anonymization. $J$ Am Med Inform Assoc. 2016;23:e131-7.

10. Lee H, Kim S, Kim JW, Chung YD. Utility-preserving anonymization for health data publishing. BMC Med Inform Decis Mak. 2017;17:104. 